\title{
Chapter 3 \\ The Genetics of Sepsis: The Promise, the Progress and the Pitfalls
}

\author{
Grant W. Waterer
}

\subsection{Introduction}

Physicians are used to taking a family history of cardiovascular disease because of the known significant hereditary risk; yet the familial risk of dying from infection is even greater than that for atherosclerotic disease (Sorensen et al. 1988). There is certainly no doubt that genetic differences impact on the risk of developing or dying from infection. Obvious but rare examples include selective immunoglobulin deficiencies, complement deficiencies, and neutrophil function abnormalities. Genetic factors may also be protective, such as with sickle cell trait and malaria or mutations conferring resistance to human immunodeficiency virus infection.

Much more subtle differences in immune responses are now being described, usually as the result of one or more single nucleotide polymorphisms (SNP) in a gene. Rather than causing the failure of production of a protein or the production of a nonfunctional protein, SNPs are usually associated with changes in the rate of transcription, producing a much less severe phenotype than the classical examples of genetic defects mentioned above. It is now being appreciated that for many complex diseases, such as sepsis, the ultimate phenotype is the result of the interaction of genetic differences across many loci, not the dominant effect of a few key mutations.

As seen in Fig. 3.1, since the mid 1990s, an increasing body of literature has focused on the role that gene polymorphisms in key inflammatory genes play in sepsis. Indeed, with advances in knowledge of the human genome, greater understanding of the inflammatory response, and the development of high throughput genotyping technologies, so many genetic associations have been described that discussion of each one is well beyond the scope of this chapter. I will however summarize those findings that have been reported by multiple groups, as well as give an overview of the major groups of genes that have been implicated in genetic predisposition to sepsis and its adverse outcomes.

Despite all this apparent growth in knowledge over the past decade however, to date not one new intervention has been developed as a result of all the genetic studies. As I will discuss, significant limitations in research methodology in published studies combined with the fact that sepsis is not a single disease make it unlikely that we 


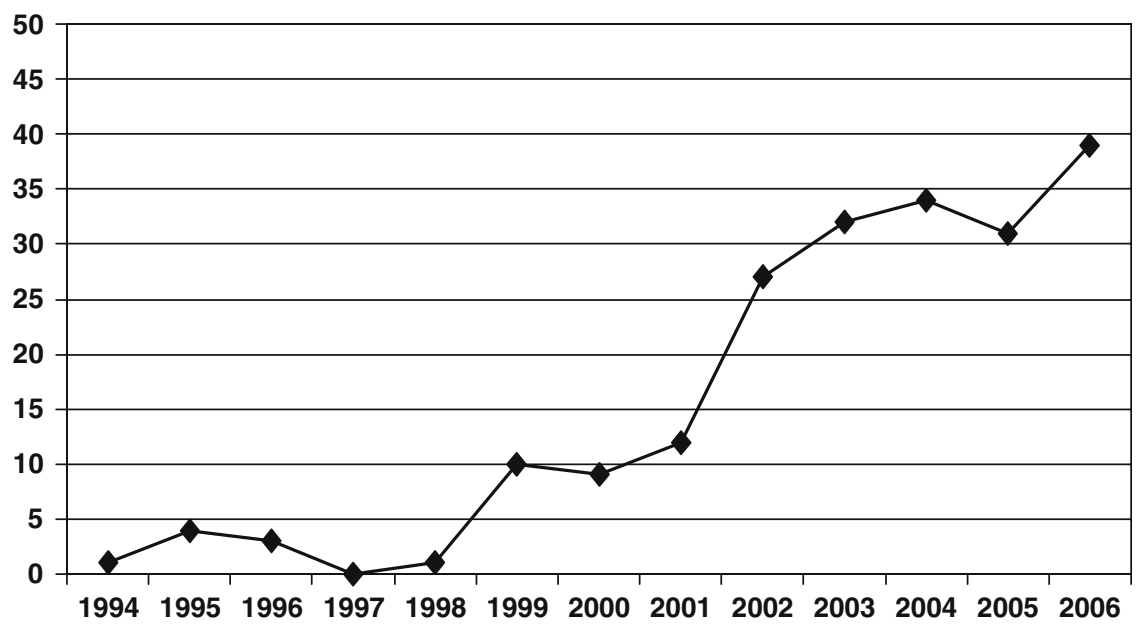

Fig. 3.1 Publications on the genetics of sepsis by year

will see any hope for new interventions in the near future. If we are to truly advance our understanding of sepsis and develop new therapeutic strategies, a substantial change in our current thinking will be required.

\subsection{Basic Genetic Terminology}

Some basic knowledge of genetic terminology is essential to decipher the sepsisgenetics literature and indeed many apparent contradictions have arisen due to terminology errors. A variety of mutations can occur in DNA, some of which leading to the change in function or production of a gene product. The simplest change is the substitution of one nucleotide for another, a SNP. A number of other mutations occur including the deletion or insertion of one or more nucleotides, including the insertion of multiple repeating sequences, sometimes called a microsatellite.

A region of DNA coding for a protein product is called an exon. Introns are the noncoding regions of DNA separating exons. Most genes consist of several exons and introns. The rate at which genes are transcribed is controlled by a variety of nuclear proteins that bind to different areas of DNA in the $5^{\prime}$ (upstream) region from the first exon. The segment of DNA controlling the regulation of transcription of a gene is also known as the promoter region.

When mutations occur in an exon they may lead to a change in the protein structure of the gene product (nonsynonymous mutation) or they may leave the protein product unchanged (synonymous mutation). When the change occurs in a promoter region, this may alter the binding of a transcription-activating or -suppressing factor, altering the rate of transcription of the gene. Although introns have been considered to be "junk DNA" and therefore mutations are likely to be of little biological importance, it is now appreciated that polymorphisms within introns can affect 
gene regulation, particularly when they are at the intron-exon boundary (Rohrer and Conely 1998; Meloni et al. 1998; Webb et al. 2003; Lenasi et al. 2006).

Most of the confusion in genetic studies is around the labeling of SNPs. Initially SNPs were assayed by amplifying up the region of DNA with the mutation by polymerase chain reaction and then using an enzyme that cut the DNA based on whether the polymorphism was present or not. Early in the genetic literature it is therefore common to see SNPs referred to by the gene and the enzyme used, for example, the tumor necrosis factor (TNF) NcoI polymorphism (subsequently known as TNF-308).

As it rapidly became apparent that there were often multiple sites within a gene that could be cleaved by the same enzyme, this nomenclature was abandoned in favor of using the nucleotide position relative to the start of the transcription site for the gene (e.g., TNF-308, TNF-238, TNF+1850, etc). This nomenclature dominated the literature for nearly a decade as it is intuitively easy to understand and the number system gives an idea of what the functional significance of the polymorphism is likely to be (e.g., a negative value places it most likely in the promoter region, a positive value in an intron or an exon). When a mutation resulted in an amino acid change in the protein, an alternative nomenclature was often substituted to reflect this (e.g., Toll-like receptor 4 (TLR4) Thr399Ile indicates that an isoleucine is substituted for a threonine at amino acid position 399).

Unfortunately, differences in calculation of the transcription start site for genes led to increasing confusion - for example, the lymphotoxin alpha (LTA, formally known as tumor necrosis factor beta) polymorphism, reported by Stuber and colleagues (1996) as a risk factor for sepsis, was variably reported as LTA+249, LTA+250, LTA +251 , and LTA +252 . With hundreds of thousands if not millions of polymorphisms now described, the accepted practice for indicating the exact polymorphism being described is currently the reference sequence number (rs\#) on the National Institutes of Health database (e.g., the TNF NcoI or -308 polymorphism is officially rs1800629). While all publications should reference the rs\#, it is likely that older terminology will continue to be used for sometime until it is more familiar.

A final problem with nomenclature that needs to be discussed is the labeling of individual alleles. There was a convention commonly seen in early genetics literature that the most common allele in the population studies was referred to as allele 1 (or A), the second most common allele 2 (or B), and so on (i.e., TNF-308 allele 1). As allele frequencies can vary significantly between populations, this has the potential to lead to considerable confusion and they should instead be referred to by the nucleotide carriage (e.g., TNF-308 A or TNF-308G) or the number of nucleotide repeats.

\subsection{Studies of Genetic Influence on the Inflammatory Response}

Genetic polymorphisms with potential influences on the inflammatory response have been identified in a variety of antigen recognition, pro- and anti-inflammatory cytokines. All of these polymorphisms are candidates for studies in genetic influences on sepsis and its outcomes, and Table 3.1 summarizes studies that have been published. 


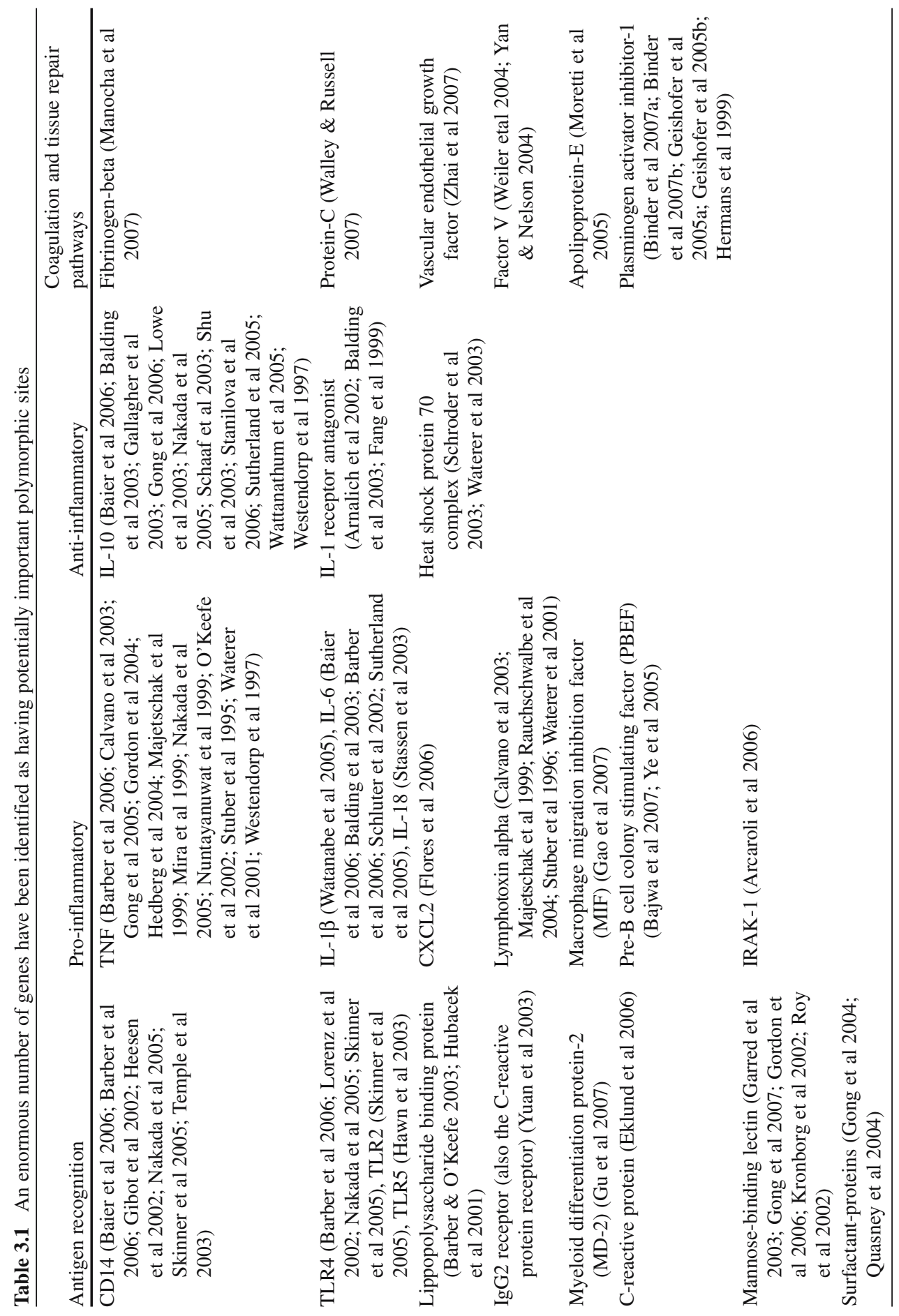


As there is substantial overlap between the functions of many cytokines, and frequently multiple antagonists for any given agonist, there is a significant ability to compensate for a certain amount of divergence in production of individual cytokines. Therefore, for a single mutation to influence the outcome of an inflammatory response, it must markedly alter the production or function of a critical inflammatory protein. While possible, the more likely scenario already discussed is the inheritance of multiple mutations in multiple proteins, each leading to small changes in production or function, interacting to lead to a net serious deleterious effect.

While a complete review of all polymorphisms described within the immune response genes is well beyond the scope of this chapter, the following section will discuss some of the key findings in various components of the immune response.

\subsubsection{Pattern Recognition Molecules}

Once the microorganism reaches the lower respiratory tract, organization of the innate immune system allows recognition of molecular patterns that are not found in humans. These so-called pattern recognition molecules (PRMs) can then initiate opsonization and lysis of microorganisms, enhance clearance by alveolar macrophages and neutrophils, as well as initiate an antibody response.

\subsubsection{Collectins}

Collectins are a family of PRMs that include surfactant proteins A and D and mannose-binding lectin (MBL), with a large degree of sequence homology present between the three compounds. MBL is the plasma form and has independent ability to activate the complement system. Conservation of MBL in various species suggests that it plays an important role in innate immunity. Several mutations in the gene itself or in the promoter region can lead to little or no serum MBL. MBL polymorphisms were found to be a risk factor for severe sepsis in adults (Garred et al. 2003), and the incidence of homozygous variant alleles in the introns was twice as common in patients with invasive pneumococcal disease in one study (Roy et al. 2002) but not in other studies (Kronborg et al. 2002). Some of the conflicting reports may be due to looking at only a limited number of polymorphisms instead of all variants or because of the significant variability in frequency of the variant alleles in different racial/ethnic groups.

\subsubsection{Toll-Like Receptors (TLRs)}

Another class of PRMs is the toll-like receptors (TLRs), human transmembrane signaling proteins equivalent to the Drosophila toll molecule found to be important in immunity against bacteria and fungi. Ten TLRs have been identified in humans, 
each with different affinities for antigens of different microorganisms (Beutler 2002). Most of the initial clinical research has focused on genetic variants of TLR4 essential for recognition of LPS. Variants in the TLR4 gene appear to increase the risk of serious gram-negative infections and sepsis (Lorenz et al. 2002). TLR4 is however unlikely to play an important role in gram-positive sepsis as TLR2 is more specific for recognition of peptidoglycans from gram-positive bacteria. Rare TLR2 polymorphisms have been described as increasing the risk of gram-positive infections (Sutherland et al. 2005b) and a TLR5 mutation has been associated with an increased risk of legionella infection (Hawn et al. 2003).

\subsubsection{Other Endotoxin Recognition Molecules}

Other key components of endotoxin recognition and signaling that have been studied as potential genetic risk factors for sepsis other than TLR4 include CD14, Myeloid differentiation protein-2 (MD-2), and lippopollysaccharide binding protein (LBP). The results for LBP gene mutations have been far from conclusive with conflicting reports (Hubacek et al. 2001; Barber and O'Keefe 2003). In contrast, studies of CD14 polymorphism have produced more consistent findings. A relatively common CD14 mutation is associated with higher soluble CD14 levels and an increased risk of septic shock ( $71 \%$ vs. $48 \%, p=0.008)$ (Gibot et al. 2002). The same polymorphism is also associated with greater TNF production after endotoxin stimulation of peripheral blood mononuclear cells in healthy adults (Temple et al. 2003a). Mutations in MD2 have also been linked with an increased risk of sepsis (Gu et al. 2007).

\subsubsection{Immunoglobulin Receptors}

Genetic variation in adaptive immunity may also play a role in sepsis. A variant in the CD32 (Fc $\gamma$ RII) subclass is associated with decreased binding of the IgG2 subclass (Yuan et al. 2003). Patients homozygous for the Fc $\gamma$ RIIa-R131 allele were more common in patients with bacteremic pneumococcal pneumonia, nonbacteremic pneumonia, or healthy controls (Yee et al. 1997). This association has been confirmed in a separate case-control study (Yuan et al. 2003). Patients with the FcyRIIa-R131 allele also appear to be more susceptible to meningococcal meningitis, as well as more susceptible to severe complications such as septic shock (van der Pol et al. 2001).

\subsubsection{Inflammatory/Anti-inflammatory Response}

\subsubsection{Tumor Necrosis Factor (TNF)}

Tumor necrosis factor (TNF) is critical to the immune response to infection (Beutler and Grau 1993), and a key driver to the development of septic shock (Bochud and 


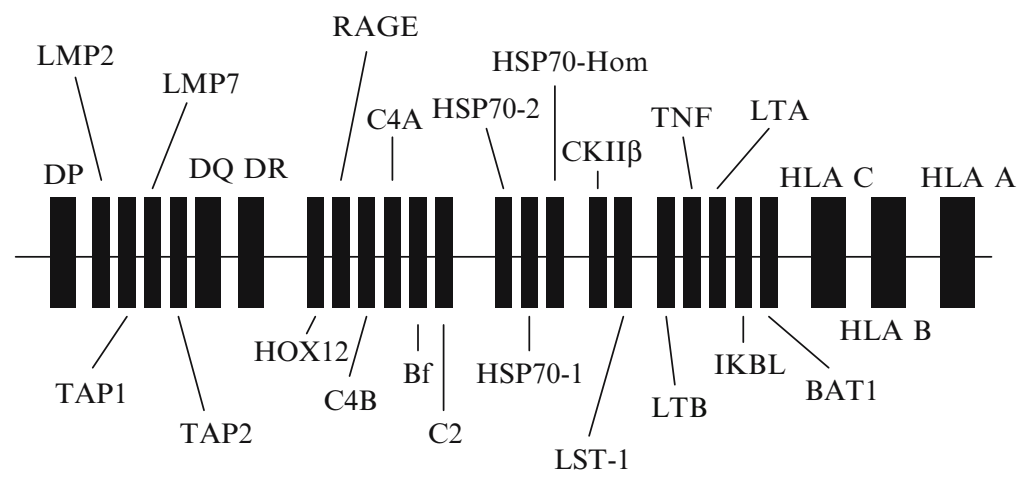

Fig. 3.2 The immunologically rich MHC region containing TNF

Calandra 2003). The TNF gene is also highly polymorphic, leading to a large array of association studies in literally hundreds of different diseases. Complicating matters further, TNF is in the immunology-gene rich area of chromosome 6 (Fig. 3.2).

The TNF-308 polymorphism is by far the most comprehensively studied genetic variation in immune response that has been reported. Carriers of the A allele ( $\mathrm{G}$ is the more common nucleotide in all populations studied) has been associated with an increased risk of death from a variety of infectious diseases, including septic shock (Azim et al. 2007; Calvano et al. 2003; Cirpriano et al. 2005; Nakada et al. 2005; Schueller et al. 2006; Mira et al. 1999; O'Keefe et al. 2002). However, other investigators have not found a significant association between the TNF-308 A allele and death from or risk of sepsis (Stuber et al. 1995; Waterer et al. 2001). The TNF-308 polymorphism is in significant linkage disequilibrium with multiple other polymorphic sites within TNF itself and in the wider MHC region. This extensive linkage disequilibrium may not only explain the disparate findings between studies, but also why after over a decade of research, there is no agreement on whether or not the different TNF-308 alleles result in differential production of TNF (Bayley et al. 2004).

\subsubsection{Lymphotoxin Alpha (LTA)}

Adenine homozygosity of LTA+252, a G to A transition in the first intron of LTA, has been associated with increased TNF production and was one of the first genetic factors identified as a potential risk factor for death from septic shock (Stuber et al. 1996; Majetschak et al. 1999). The same genotype has also been associated with an increased risk of septic shock in patients with pneumonia (Waterer et al. 2001). In the latter study, it was interesting that respiratory failure correlated with the GG genotype (Waterer et al. 2001), the opposite of the association for shock. However, given LTA +252 is located in an intron, the association with variable TNF production is most likely due to linkage disequilibrium with other variant alleles in the TNF, LTA, or other nearby genes. 


\subsubsection{Interleukin - 1 (IL-1) Family}

The IL- 1 gene family includes the potent inflammatory agonists IL- $1 \alpha$ and IL-1 $\beta$, and the IL-1 receptor antagonist (IL-1RN), adjacent to each other on the same chromosome and therefore there is marked linkage disequilibrium between polymorphisms within the three genes. Two SNPs, the IL-1 $\beta+3953$ and -511 , which have both been suggested to influence levels of IL-1 $\beta$ (Pociot et al. 1992), were associated with increased risk of death from meningococcal infection in one cohort study (Read et al. 2000) but not with susceptibility to or outcome from septic shock (Fang et al. 1999). In contrast, variants of the IL-1RN gene have been demonstrated to have an excess mortality in septic patients in three sepsis studies in different ethnic groups (Fang et al. 1999; Arnalich et al. 2002; Ma et al. 2002; Turner et al. 1997), although these studies did not assess potential coinherited polymorphisms in IL- $1 \alpha$ and IL- $1 \beta$ making it difficult to be sure the associations observed were attributable to the IL-1-RN variants.

\subsubsection{Interleukin 10 (IL-10)}

IL-10 is another highly polymorphic gene. Three promoter polymorphisms (-1082/819/-592) have been extensively studied and different -819/-592 haplotypes associated with variable IL-10 production (Turner et al. 1997). The effect of the IL-10 haplotype however appears to be pathogen-dependent, with a significantly different genotype-phenotype relationship observed depending on whether the stimulus is gram-positive or gram-negative (Temple et al. 2003b).

Several case-control studies have suggested that carriage of the IL-10 -1082G allele is a significant risk factor for adverse outcome in patients with pneumonia (Gallagher et al. 2003; Schaaf et al. 2003). Case-control studies also suggest that the IL-10-1082 G allele is a risk factor for death from septic shock (Stanilolva et al. 2006), and a risk factor for multiorgan dysfunction after major trauma (Schroder et al. 2004).

\subsubsection{Heat Shock Protein}

While intracellular heat shock proteins (HSPs) principally play a cytoprotective role, extracellular HSP70 can induce a proinflammatory response through TLR2 and TLR4 via a CD14-dependent mechanism. As shown in Fig. 3.2, the HSP-70 locus is also close to the TNF and LTA loci. A significant association between the A allele of HSPA1B+1267 and septic shock has been demonstrated in an extension of the pneumonia study mentioned above (Waterer et al. 2003), which was even stronger than that of the LTA+252. This stronger association, combined with functional studies showing that the HSP-A1B polymorphism was associated with variable HSP-70 production and TNF production (Temple et al. 2004) strongly suggests that this is the "real" cause of the associations described with LTA+252. 


\subsubsection{Coagulation Pathway Proteins}

An extremely large number of polymorphisms have now been described within the pro- and anticoagulant hemostatic pathways, many of which being suggested to influence coagulation. With the increase in interest in the role of coagulation in the outcome of severe sepsis due to the success of activated protein-C (Bernard et al. 2001), it is not surprising that there has been an increase in interest in genetic differences in coagulation pathways and the risk of sepsis.

An insertion/deletion polymorphism in plasminogen activation inhibitor (PAI)-1 is associated with variation in serum PAI-1 levels (Ye et al. 1995) and has been suggested as a significant risk factor for mortality in children with meningococcal disease (Binder et al. 2007; Geishofer et al. 2005; Haralambous et al. 2003). One study in adults also suggests that the same polymorphism is a risk factor for death from septic shock in caucasians (Garcia-Segarra et al. 2007; Hermans et al. 1999).

\subsection{Problems with Genetic Studies in Sepsis}

What explains the diversity of findings in studies of genetic influence on sepsis? There is no doubt that simple genotyping error, particularly before the advent of highly automated platforms, is a significant source of error in polymorphism studies (Clark and Baudouin 2006; Sutherland and Russell 2005; Peters et al. 2003). As early studies typically contained less than 100 subjects, even a few genotyping errors, particularly with rare genotypes, can have a dramatic impact on statistical significance. It is important that all genetic studies perform and report adequate quality control measures to ensure genotyping is accurate.

The problems of linkage disequilibrium have been mentioned several times. As the human genome is so highly polymorphic, the likelihood that any studied polymorphism is the "real" site of significance is low. Newer genetic methods, particularly genotyping multiple nearby SNPs to determine the "length" of DNA associated with the clinical outcome (known as haplotype mapping) are a significant aid in trying to determine the key genetic area.

As already discussed with TNF-308, actually proving that a polymorphism is functionally significant is a very difficult task unless the polymorphism results in a change in the protein structure. There are numerous examples of different groups claiming that a polymorphism is (or is not) functionally important based on different stimuli, cell types, and sample timing.

Compounding the difficulty in finding associations is that even if a polymorphism results in a functional change in the production of a key protein, this could have both detrimental and beneficial effects depending on the outcome concerned. For example, a propensity to greater TNF may be protective in reducing the risk of developing infection; however, if pneumonia becomes established, it may predispose to a greater risk of acute respiratory distress syndrome or septic shock. 
Another problem limiting the development of new therapeutic strategies arising from genetic studies is the timing of the influence of the polymorphism. For example, TNF polymorphisms may be important in the risk of septic shock; however, as the failed randomized controlled trials of anti-TNF antibodies demonstrated, once septic shock is established, modifying TNF production has no benefit. Many genetic factors predisposing to an initial event are likely to suffer from the same problem given that patients typically present well after infection has been established.

Finally, the number of polymorphisms already reported as being "important" is significant. Studies that address only one or two polymorphisms without studying previously reported polymorphisms so that the new findings can be put into a relative context do little to advance our knowledge (Waterer 2007). Unfortunately, given the issues with multiple testing, the sample size to sort out the relative contributions of all these polymorphisms is in tens of thousands.

\subsection{Summary}

There is an increasing array of polymorphisms in diverse inflammatory genes that have been identified as candidates to explain genetic variability in susceptibility to septic shock and its adverse outcomes. Unfortunately, to date, the ever-expanding volume of publications has not led to any new therapeutic insights. The failure to advance to the "next step" is due in part to failings of published studies, but mostly because of the fact that sepsis is almost certainly the result of hundreds, if not thousands, of mutations that each contribute in a small way to a very complex phenotype. Future studies will hopefully learn from the mistakes of the past and realize the enormous promise of genetic studies.

\section{References}

Arcaroli, J., E. Silva, J. Maloney, Q. He, D. Svetkauskaite, J. Murphy, and E. Abraham. 2006. Variant IRAK-1 haplotype is associated with increased nuclear factor-kappaB activation and worse outcomes in sepsis. Am J Respir Crit Care Med 173:1335-41.

Arnalich, F., D. Lopez-Maderuelo, R. Codoceo, J. Lopez, L. M. Solis-Garrido, C. Capiscol, C. Fernandez-Capitan, R. Madero, and C. Montiel. 2002. Interleukin-1 receptor antagonist gene polymorphism and mortality in patients with severe sepsis. Clin Exp Immunol 127:331-6.

Azim, K., R. McManus, K. Brophy, A. Ryan, D. Kelleher, and J. V. Reynolds. 2007. Genetic polymorphisms and the risk of infection following esophagectomy. Positive association with TNFalpha gene -308 genotype. Ann Surg 246:122-8.

Baier, R., J. Loggins, and K. Yanamandra. 2006. IL-10, IL-6 and CD14 polymorphisms and sepsis outcome in ventilated very low birth weight infants. BMC Med 12:10-12.

Bajwa, E., C. Yu, M. Gong, B. Thompson, and D. Christiani. 2007. Pre-B-cell colony-enhancing factor gene polymorphisms and risk of acute respiratory distress syndrome. Crit Care Med 35:1290-5. 
Balding, J., C. M. Healy, W. J. Livingstone, B. White, L. Mynett-Johnson, M. Cafferkey, and O. P. Smith. 2003. Genomic polymorphic profiles in an Irish population with meningococcaemia: is it possible to predict severity and outcome of disease? Genes Immun 4:533-40.

Barber, R., L. Chang, B. D. Arnoldo, G. Purdue, J. Hunt, J. Horton, and C. Aragaki. 2006. Innate immunity SNPs are associated with risk for severe sepsis after burn injury. Clin Med Res 4:250-5.

Barber, R. C., and G. E. O'Keefe. 2003. Characterization of a single nucleotide polymorphism in the lipopolysaccharide binding protein and its association with sepsis. Am J Respir Crit Care Med 167:1316-20.

Bayley, J. P., T. H. Ottenhoff, and C. L. Verweij. 2004. Is there a future for TNF promoter polymorphisms? Genes Immun 5:315-29.

Bernard, G. R., J. L. Vincent, P. F. Laterre, S. P. LaRosa, J. F. Dhainaut, A. Lopez-Rodriguez, J. S. Steingrub, G. E. Garber, J. D. Helterbrand, E. W. Ely, and C. J. Fisher, Jr. 2001. Efficacy and safety of recombinant human activated protein $\mathrm{C}$ for severe sepsis. $N$ Engl J Med 344:699-709.

Beutler, B. 2002. Toll-like receptors: how they work and what they do. Curr Opin Hematol 9:2-10.

Beutler, B., and G. E. Grau. 1993. Tumor necrosis factor in the pathogenesis of infectious diseases. Crit Care Med 21(10 Suppl):S423-35.

Binder, A., G. Endler, M. Muller, C. Mannhalter, and W. Zenz. 2007. 4G4G genotype of the plasminogen activator inhibitor-1 promoter polymorphism associates with disseminated intravascular coagulation in children with systemic meningococcemia. J Thromb Haemost 5:2049-54.

Bochud, P. Y., and T. Calandra. 2003. Pathogenesis of sepsis: new concepts and implications for future treatment. BMJ 326(7383):262-6.

Calvano, J. E., J. Y. Um, D. M. Agnese, S. J. Hahm, A. Kumar, S. M. Coyle, S. E. Calvano, and S. F. Lowry. 2003. Influence of the TNF-alpha and TNF-beta polymorphisms upon infectious risk and outcome in surgical intensive care patients. Surg Infect (Larchmt) 4:163-9.

Cipriano, C., C. Caruso, D. Lio, R. Giacconi, M. Malavolta, E. Muti, N. Gasparini, C. Franceschi, and E. Mocchegiani. 2005. The -308G/A polymorphism of TNF-alpha influences immunological parameters in old subjects affected by infectious diseases. Int J Immunogenet 32:13-18.

Clark, M., and S. Baudouin. 2006. A systematic review of the quality of genetic association studies in human sepsis. Intensive Care Med 32:1679-80.

Eklund, C., R. Huttunen, J. Syrjänen, J. Laine, R. Vuento, and M. Hurme. 2006. Polymorphism of the C-reactive protein gene is associated with mortality in bacteraemia. Scand J Infect Dis 38(11-12):1069-73.

Fang, X. M., S. Schroder, A. Hoeft, and F. Stuber. 1999. Comparison of two polymorphisms of the interleukin-1 gene family: interleukin-1 receptor antagonist polymorphism contributes to susceptibility to severe sepsis. Crit Care Med 27:1330-4.

Flores, C., N. Maca-Meyer, L. Pérez-Méndez, R. Sangüesa, E. Espinosa, A. Muriel, J. Blanco, J. Villar, G. group, and G.- S. group. 2006. A CXCL2 tandem repeat promoter polymorphism is associated with susceptibility to severe sepsis in the Spanish population. Genes Immun 7:141-9.

Gallagher, P. M., G. Lowe, T. Fitzgerald, A. Bella, C. M. Greene, N. G. McElvaney, and S. J. O'Neill. 2003. Association of IL-10 polymorphism with severity of illness in community acquired pneumonia. Thorax 58:154-6.

Gao, L., C. Flores, S. Fan-Ma, E. Miller, J. Moitra, L. Moreno, R. Wadgaonkar, B. Simon, R. Brower, J. Sevransky, R. Tuder, J. Maloney, M. Moss, C. Shanholtz, C. Yates, G. Meduri, S. Ye, K. Barnes, and J. Garcia. 2007. Macrophage migration inhibitory factor in acute lung injury: expression, biomarker, and associations. Transl Res 150:18-29.

Garcia-Segarra, G., G. Espinosa, D. Tassies, J. Oriola, J. Aibar, A. Bove, P. Castro, J. C. Reverter, and J. M. Nicolas. 2007. Increased mortality in septic shock with the $4 \mathrm{G} / 4 \mathrm{G}$ genotype of plasminogen activator inhibitor 1 in patients of white descent. Intensive Care Med 33:1354-62. 
Garred, P., J. Strøm, L. Quist, E. Taaning, and H. Madsen. 2003. Association of mannose-binding lectin polymorphisms with sepsis and fatal outcome, in patients with systemic inflammatory response syndrome. J Infect Dis 188:1394-1403.

Geishofer, G., A. Binder, M. Muller, B. Zohrer, B. Resch, W. Muller, J. Faber, A. Finn, G. Endler, C. Mannhalter, W. Zenz, and C. E. M. G. S. Group. 2005. 4G/5G promoter polymorphism in the plasminogen-activator-inhibitor-1 gene in children with systemic meningococcaemia. Eur J Pediatr 164:486-90.

Gibot, S., A. Cariou, L. Drouet, M. Rossignol, and L. Ripoll. 2002. Association between a genomic polymorphism within the CD14 locus and septic shock susceptibility and mortality rate. Crit Care Med 30:969-73.

Gong, M. N., Z. Wei, L. L. Xu, D. P. Miller, B. T. Thompson, and D. C. Christiani. 2004. Polymorphism in the surfactant protein-B gene, gender, and the risk of direct pulmonary injury and ARDS. Chest 125:203-11.

Gong, M. N., W. Zhou, P. L. Williams, B. T. Thompson, L. Pothier, P. Boyce, and D. C. Christiani. 2005. -308GA and TNFB polymorphisms in acute respiratory distress syndrome. Eur Respir $J$ 26:382-9.

Gong, M. N., B. T. Thompson, P. L. Williams, W. Zhou, M. Z. Wang, L. Pothier, and D. C. Christiani. 2006. Interleukin-10 polymorphism in position -1082 and acute respiratory distress syndrome. Eur Respir J 27:674-81.

Gong, M. N., W. Zhou, P. L. Williams, B. T. Thompson, L. Pothier, and D. C. Christiani. 2007. Polymorphisms in the mannose binding lectin-2 gene and acute respiratory distress syndrome. Crit Care Med 35:48-56.

Gordon, A. C., A. L. Lagan, E. Aganna, L. Cheung, C. J. Peters, M. F. McDermott, J. L. Millo, K. I. Welsh, P. Holloway, G. A. Hitman, R. D. Piper, C. S. Garrard, and C. J. Hinds. 2004. TNF and TNFR polymorphisms in severe sepsis and septic shock: a prospective multicentre study. Genes Immun 5:631-40.

Gordon, A., U. Waheed, T. Hansen, G. Hitman, C. Garrard, M. Turner, N. Klein, S. Brett, and C. Hinds. 2006. Mannose-binding lectin polymorphisms in severe sepsis: relationship to levels, incidence, and outcome. Shock 25:88-93.

Gu, W., Y. Shan, J. Zhou, D. Jiang, L. Zhang, D. Du, Z. Wang, and J. Jiang. 2007. Functional significance of gene polymorphisms in the promoter of myeloid differentiation-2. Ann Surg 246:151-8.

Haralambous, E., M. L. Hibberd, P. W. Hermans, N. Ninis, S. Nadel, and M. Levin. 2003. Role of functional plasminogen-activator-inhibitor-1 4G/5G promoter polymorphism in susceptibility, severity, and outcome of meningococcal disease in Caucasian children. Crit Care Med 31:2788-93.

Hawn, T. R., A. Verbon, K. D. Lettinga, L. P. Zhao, S. S. Li, R. J. Laws, S. J. Skerrett, B. Beutler, L. Schroeder, A. Nachman, A. Ozinsky, K. D. Smith, and A. Aderem. 2003. A common dominant TLR5 stop codon polymorphism abolishes flagellin signaling and is associated with susceptibility to legionnaires' disease. J Exp Med 198:1563-72.

Hedberg, C. L., K. Adcock, J. Martin, J. Loggins, T. E. Kruger, and R. J. Baier. 2004. Tumor necrosis factor alpha -308 polymorphism associated with increased sepsis mortality in ventilated very low birth weight infants. Pediatr Infect Dis $J$ 23:424-8.

Heesen, M., B. Bloemeke, U. Schade, U. Obertacke, and M. Majetschak. 2002. The $-260 \mathrm{C} \rightarrow \mathrm{T}$ promoter polymorphism of the lipopolysaccharide receptor CD14 and severe sepsis in trauma patients. Intensive Care Med 28:1161-3.

Hermans, P. W., M. L. Hibberd, R. Booy, O. Daramola, J. A. Hazelzet, R. de Groot, and M. Levin. 1999. 4G/5G promoter polymorphism in the plasminogen-activator-inhibitor-1 gene and outcome of meningococcal disease. Meningococcal Research Group. Lancet 354(9178):556-60.

Hubacek, J. A., F. Stuber, D. Frohlich, M. Book, S. Wetegrove, M. Ritter, G. Rothe, and G. Schmitz. 2001. Gene variants of the bactericidal/permeability increasing protein and lipopolysaccharide binding protein in sepsis patients: gender-specific genetic predisposition to sepsis. Crit Care Med 29:557-61.

Kronborg, G., N. Weis, H. Madsen, S. Pedersen, C. Wejse, H. Nielsen, et al. 2002. Variant mannose-binding lectin alleles are not associated with susceptibility to or outcome of invasive pneumococcal infection in randomly included patients. J Infect Dis 185:1517-20. 
Lenasi, T., B. M. Peterlin, and P. Dovc. 2006. Distal regulation of alternative splicing by splicing enhancer in equine beta-casein intron 1. RNA 12:498-507.

Lorenz, E., J. Mira, K. Frees, and D. Schwartz. 2002. Relevance of mutations in the TLR4 receptor in patients with gram-negative septic shock. Arch Intern Med 162:1028-32.

Lowe, P. R., H. F. Galley, A. Abdel-Fattah, and N. R. Webster. 2003. Influence of interleukin-10 polymorphisms on interleukin-10 expression and survival in critically ill patients. Crit Care Med 31:34-8.

Ma, P., D. Chen, J. Pan, and B. Du. 2002. Genomic polymorphism within interleukin-1 family cytokines influences the outcome of septic patients. Zhonghua Yi Xие Za Zhi 82:1237-41.

Majetschak, M., S. Flohe, U. Obertacke, J. Schroder, K. Staubach, D. Nast-Kolb, F. U. Schade, and F. Stuber. 1999. Relation of a TNF gene polymorphism to severe sepsis in trauma patients. Ann Surg 230:207-14.

Manocha, S., J. Russell, A. Sutherland, A. Wattanathum, and K. Walley. 2007. Fibrinogen-beta gene haplotype is associated with mortality in sepsis. J Infect 54:572-7.

Meloni, R., V. Albanese, P. Ravassard, F. Treilhou, and J. Mallet. 1998. A tetranucleotide polymorphic microsatellite, located in the first intron of the tyrosine hydroxylase gene, acts as a transcription regulatory element in vitro. Hum Mol Genet 7:423-8.

Mira, J. P., A. Cariou, F. Grall, C. Delclaux, M. R. Losser, F. Heshmati, C. Cheval, M. Monchi, J. L. Teboul, F. Riche, G. Leleu, L. Arbibe, A. Mignon, M. Delpech, and J. F. Dhainaut. 1999. Association of TNF2, a TNF-alpha promoter polymorphism, with septic shock susceptibility and mortality: a multicenter study. JAMA 282:561-8.

Moretti, E. W., R. W. Morris, M. Podgoreanu, D. A. Schwinn, M. F. Newman, E. Bennett, V. G. Moulin, U. U. Mba, and D. T. Laskowitz. 2005. APOE polymorphism is associated with risk of severe sepsis in surgical patients. Crit Care Med 33:2521-6.

Nakada, T. A., H. Hirasawa, S. Oda, H. Shiga, K. I. Matsuda, M. Nakamura, E. Watanabe, R. Abe, M. Hatano, and T. Tokuhisa. 2005. Influence of toll-like receptor 4, CD14, tumor necrosis factor, and interleukine-10 gene polymorphisms on clinical outcome in Japanese critically ill patients. J Surg Res 129:322-8.

Nuntayanuwat, S., T. Dharakul, W. Chaowagul, and S. Songsivilai. 1999. Polymorphism in the promoter region of tumor necrosis factor-alpha gene is associated with severe meliodosis. Hum Immunol 60:979-83.

O'Keefe, G. E., D. L. Hybki, and R. S. Munford. 2002. The G $\rightarrow$ A single nucleotide polymorphism at the -308 position in the tumor necrosis factor-alpha promoter increases the risk for severe sepsis after trauma. J Trauma 52:817-25; discussion 825-6.

Peters, D. L., R. C. Barber, E. M. Flood, H. R. Garner, and G. E. O'Keefe. 2003. Methodologic quality and genotyping reproducibility in studies of tumor necrosis factor $-308 * * * * \mathrm{G} \rightarrow \mathrm{A}$ single nucleotide polymorphism and bacterial sepsis: implications for studies of complex traits. Crit Care Med 31:1691-6.

Pociot, F., J. Molvig, L. Wogensen, H. Worsaae, and J. Nerup. 1992. A TaqI polymorphism in the human interleukin-1 beta (IL-1 beta) gene correlates with IL-1 beta secretion in vitro. Eur J Clin Invest 22:396-402.

Quasney, M. W., G. W. Waterer, M. K. Dahmer, G. K. Kron, Q. Zhang, L. A. Kessler, and R. G. Wunderink. 2004. Association between surfactant protein B+1580 polymorphism and the risk of respiratory failure in adults with community-acquired pneumonia. Crit Care Med 32:1115-19.

Rauchschwalbe, S. K., T. Maseizik, U. Mittelkotter, B. Schluter, C. Patzig, A. Thiede, and H. B. Reith. 2004. Effect of the LT-alpha (+250 G/A) polymorphism on markers of inflammation and clinical outcome in critically ill patients. $J$ Trauma 56:815-22.

Read, R. C., N. J. Camp, F. S. di Giovine, R. Borrow, E. B. Kaczmarski, A. G. Chaudhary, A. J. Fox, and G. W. Duff. 2000. An interleukin-1 genotype is associated with fatal outcome of meningococcal disease. J Infect Dis 182:1557-60.

Rohrer, J., and M. E. Conley. 1998. Transcriptional regulatory elements within the first intron of Bruton's tyrosine kinase. Blood 91:214-21.

Roy, S., K. Knox, S. Segal, D. Griffiths, C. Moore, K. Welsh, et al. 2002. MBL genotype and risk of invasive pneumococcal disease: a case-control study. Lancet 359(9317):1569-73. 
Schaaf, B. M., F. Boehmke, H. Esnaashari, U. Seitzer, H. Kothe, M. Maass, P. Zabel, and K. Dalhoff. 2003. Pneumococcal septic shock is associated with the interleukin-10-1082 gene promoter polymorphism. Am J Respir Crit Care Med 168:476-80.

Schluter, B., C. Raufhake, M. Erren, H. Schotte, F. Kipp, S. Rust, H. Van Aken, G. Assmann, and E. Berendes. 2002. Effect of the interleukin-6 promoter polymorphism $(-174 \mathrm{G} / \mathrm{C})$ on the incidence and outcome of sepsis. Crit Care Med 30:32-7.

Schroder, O., K. M. Schulte, P. Ostermann, H. D. Roher, A. Ekkernkamp, and R. A. Laun. 2003. Heat shock protein 70 genotypes HSPA1B and HSPA1L influence cytokine concentrations and interfere with outcome after major injury. Crit Care Med 31:73-9.

Schroder, O., R. A. Laun, B. Held, A. Ekkernkamp, and K. M. Schulte. 2004. Association of interleukin-10 promoter polymorphism with the incidence of multiple organ dysfunction following major trauma: results of a prospective pilot study. Shock 21:306-10.

Schueller, A. C., A. Heep, E. Kattner, M. Kroll, M. Wisbauer, J. Sander, P. Bartmann, and F. Stuber. 2006. Prevalence of two tumor necrosis factor gene polymorphisms in premature infants with early onset sepsis. Biol Neonate 90:229-32.

Shu, Q., X. Fang, Q. Chen, and F. Stuber. 2003. IL-10 polymorphism is associated with increased incidence of severe sepsis. Chin Med J (Engl) 116:1756-9.

Skinner, N. A., C. M. MacIsaac, J. A. Hamilton, and K. Visvanathan. 2005. Regulation of toll-like receptor (TLR)2 and TLR4 on CD14dimCD16+ monocytes in response to sepsis-related antigens. Clin Exp Immunol 141:270-8.

Sorensen, T. I., G. G. Nielsen, P. K. Andersen, and T. W. Teasdale. 1988. Genetic and environmental influences on premature death in adult adoptees. N Engl J Med 318:727-32.

Stanilova, S. A., L. D. Miteva, Z. T. Karakolev, and C. S. Stefanov. 2006. Interleukin-10-1082 promoter polymorphism in association with cytokine production and sepsis susceptibility. Intensive Care Med 32:260-6.

Stassen, N. A., C. M. Breit, L. A. Norfleet, and H. C. Polk, Jr. 2003. IL-18 promoter polymorphisms correlate with the development of post-injury sepsis. Surgery 134:351-6.

Stuber, F., I. A. Udalova, M. Book, L. N. Drutskaya, D. V. Kuprash, R. L. Turetskaya, F. U. Schade, and S. A. Nedospasov. 1995. -308 tumor necrosis factor (TNF) polymorphism is not associated with survival in severe sepsis and is unrelated to lipopolysaccharide inducibility of the human TNF promoter. J Inflamm 46:42-50.

Stuber, F., M. Petersen, F. Bokelmann, and U. Schade. 1996. A genomic polymorphism within the tumor necrosis factor locus influences plasma tumor necrosis factor-alpha concentrations and outcome of patients with severe sepsis. Crit Care Med 24:381-4.

Sutherland, A. M., and J. A. Russell. 2005. Issues with polymorphism analysis in sepsis. Clin Infect Dis 41(7 Suppl):S396-402.

Sutherland, A. M., K. R. Walley, and J. A. Russell. 2005a. Polymorphisms in CD14, mannosebinding lectin, and toll-like receptor-2 are associated with increased prevalence of infection in critically ill adults. Crit Care Med 33:638-44.

Sutherland, A. M., K. R. Walley, S. Manocha, and J. A. Russell. 2005b. The association of interleukin 6 haplotype clades with mortality in critically ill adults. Arch Intern Med 165:75-82.

Temple, S. E., K. Y. Cheong, C. M. Almeida, P. Price, and G. W. Waterer. 2003a. Polymorphisms in lymphotoxin alpha and CD14 genes influence TNF alpha production induced by Gram-positive and Gram-negative bacteria. Genes Immun 4:283-8.

Temple, S. E., E. Lim, K. Y. Cheong, C. A. Almeida, P. Price, K. G. Ardlie, and G. W. Waterer. 2003b. Alleles carried at positions -819 and -592 of the IL10 promoter affect transcription following stimulation of peripheral blood cells with Streptococcus pneumoniae. Immunogenetics 55:629-32.

Temple, S. E., K. Y. Cheong, K. G. Ardlie, D. Sayer, and G. W. Waterer. 2004. The septic shock associated HSPA1B1267 polymorphism influences production of HSPA1A and HSPA1B. Intensive Care Med 30:1761-7.

Turner, D. M., D. M. Williams, D. Sankaran, M. Lazarus, P. J. Sinnott, and I. V. Hutchinson. 1997. An investigation of polymorphism in the interleukin-10 gene promoter. Eur J Immunogenet $24: 1-8$. 
van der Pol, W. L., T. W. Huizinga, G. Vidarsson, M. W. van der Linden, M. D. Jansen, V. Keijsers, F. G. de Straat, N. A. Westerdaal, J. G. de Winkel, and R. G. Westendorp. 2001. Relevance of Fcgamma receptor and interleukin-10 polymorphisms for meningococcal disease. J Infect Dis 184:1548-55.

Walley, K., and J. Russell. 2007. Protein C -1641 AA is associated with decreased survival and more organ dysfunction in severe sepsis. Crit Care Med 35:12-17.

Watanabe, E., H. Hirasawa, S. Oda, K. Matsuda, M. Hatano, and T. Tokuhisa. 2005. Extremely high interleukin-6 blood levels and outcome in the critically ill are associated with tumor necrosis factor- and interleukin-1-related gene polymorphisms. Crit Care Med 33:89-97; discussion $242-3$.

Waterer, G. W. 2007. Polymorphism studies in critical illness - we have to raise the bar. Crit Care Med 35:1424-5.

Waterer, G. W., M. W. Quasney, R. M. Cantor, and R. G. Wunderink. 2001. Septic shock and respiratory failure in community-acquired pneumonia have different TNF polymorphism associations. Am J Respir Crit Care Med 163:1599-604.

Waterer, G. W., L. ElBahlawan, M. W. Quasney, Q. Zhang, L. A. Kessler, and R. G. Wunderink. 2003. Heat shock protein 70-2+1267 AA homozygotes have an increased risk of septic shock in adults with community-acquired pneumonia. Crit Care Med 31:1367-72.

Wattanathum, A., S. Manocha, H. Groshaus, J. A. Russell, and K. R. Walley. 2005. Interleukin-10 haplotype associated with increased mortality in critically ill patients with sepsis from pneumonia but not in patients with extrapulmonary sepsis. Chest 128:1690-8.

Webb, K. E., J. F. Martin, J. Cotton, J. D. Erusalimsky, and S. E. Humphries. 2003. The 4830C > A polymorphism within intron 5 affects the pattern of alternative splicing occurring within exon 6 of the thrombopoietin gene. Exp Hematol 31:488-94.

Weiler, H., B. Kerlin, and M. C. Lytle. 2004. Factor V Leiden polymorphism modifies sepsis outcome: evidence from animal studies. Crit Care Med 32(5 Suppl):S233-8.

Westendorp, R. G., J. A. Langermans, T. W. Huizinga, A. H. Elouali, C. L. Verweij, D. I. Boomsma, and J. P. Vandenbroucke. 1997. Genetic influence on cytokine production and fatal meningococcal disease. Lancet 349(9046):170-3.

Yan, S. B., and D. R. Nelson. 2004. Effect of factor V Leiden polymorphism in severe sepsis and on treatment with recombinant human activated protein C. Crit Care Med 32(5 Suppl):S239-46.

Ye, S., F. R. Green, P. Y. Scarabin, V. Nicaud, L. Bara, S. J. Dawson, S. E. Humphries, A. Evans, G. Luc, J. P. Cambou, et al. 1995. The 4G/5G genetic polymorphism in the promoter of the plasminogen activator inhibitor-1 (PAI-1) gene is associated with differences in plasma PAI-1 activity but not with risk of myocardial infarction in the ECTIM study. Etude CasTemoins de I'nfarctus du Mycocarde. Thromb Haemost 74:837-41.

Ye, S. Q., B. A. Simon, J. P. Maloney, A. Zambelli-Weiner, L. Gao, A. Grant, R. B. Easley, B. J. McVerry, R. M. Tuder, T. Standiford, R. G. Brower, K. C. Barnes, and J. G. Garcia. 2005. PreB-cell colony-enhancing factor as a potential novel biomarker in acute lung injury. Am J Respir Crit Care Med 171:361-70.

Yee, A. M., S. C. Ng, R. E. Sobel, and J. E. Salmon. 1997. Fc gammaRIIA polymorphism as a risk factor for invasive pneumococcal infections in systemic lupus erythematosus. Arthritis Rheum 40:1180-2.

Yuan, F. F., M. Wong, N. Pererva, J. Keating, A. R. Davis, J. A. Bryant, and J. S. Sullivan. 2003. FcgammaRIIA polymorphisms in Streptococcus pneumoniae infection. Immunol Cell Biol 81:192-5.

Zhai, R., M. N. Gong, W. Zhou, T. B. Thompson, P. Kraft, L. Su, and D. C. Christiani. 2007. Genotypes and haplotypes of VEGF gene are associated with higher ARDS mortality and lower VEGF plasma levels. Thorax 62:718-22. 